vation that any interested person can make of the birds in a farm shelterbelt. Much more could be done by someone making an intensive life history or behaviour study. The unit of study is so restricted that it may seem entirely insignificant; but it is to be remembered that observations in a limited local area produced Malcolm MacDonald's Birds of Brewery Creek and Gilbert White's Natural History of Selborne.

\section{NEST RECORD CARDS}

Please send your nest records in immediately so that a summary of this year's information may be prepared for the De-. cember issue of the Blue Jay. Cards should be sent to the Saskatchewan Museum of Natural History, Regina.

\title{
PROTECTIVE COLORATION OF THE WESTERN MEADOWLARY
}

\section{By Ono F. Lick, Davidson, Sask.}

Yesterday, as I sat facing an old window overlooking a shaggy piece of sod, I saw a bird flying downward as if going to alight. By its size, its streaked brownish back and white outer tail feathers, I took it to be a meadowlark. My mind became conscious of cats, so I looked more closely. ready to alert the bird by tapping on the window pane. The sod (I cannot give it the dignified name of lawn) looked very rumpled and tousled, with clumps of old, brown srested wheat grass, fresh green grass underneath and a big patch of prairie beans. I could see no meadowlark. The breeze kept the yellow blossoms of the beans moving. The longer I watched, the more deter mined I became to spot the yellow breasted bird. After watching for fiv minutes, I became bolder and pulle the window curtain aside. Only the did the bird display itself by flyin up. It was an example of remarkiabl protective coloring, the brown of th bird resembling the tufts of dea crested wheat grass and the yellor blossoms of the beans.

I have observed this protective col oring on many occasions. A few year ago I was watching a swarm of fritil lary butterflies amid a patch of dan delions. Walking around among th nodding dandelion heads, scarcel noticeable, was a meadowlark, grab bing off the fritillaries.

\section{MALLARD NESTS IN ABANDONED CROW'S NEST IN ASPEN TRE}

\section{By Frank Roy, Saskatoon}

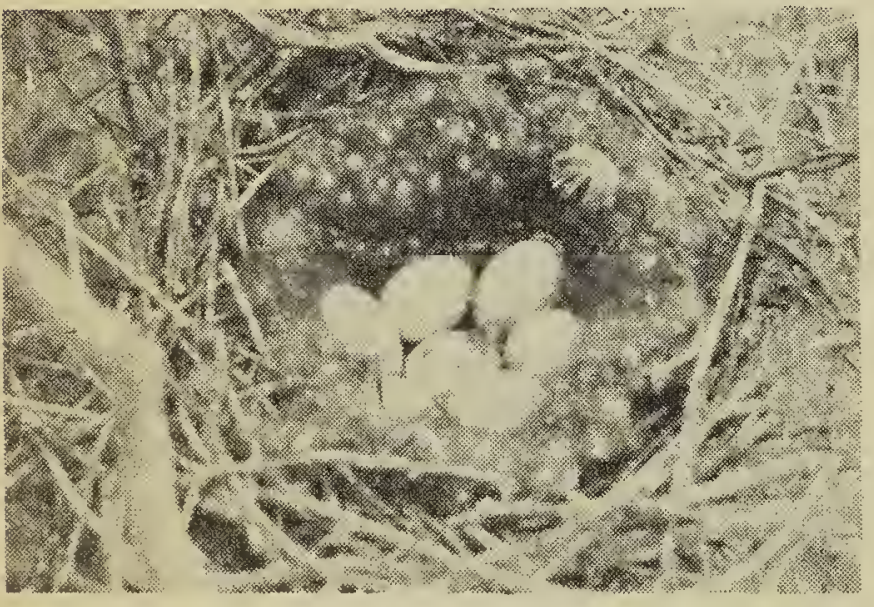

On June 8, 1958, Mr. Bob Darcy, 1340 Colony Street, Saskatoon, reported to me that he had discovered a duck nesting in an abandoned crow's nest in an aspen tree about two miles east of the city on Eighth Street. The crow's nest situated aibout 16 feet up in a 24 -foot aspen, was well preserved and amply line with down. When I observed the ne: on June 8, it contained 7 eggs. Yol on several of the eggs indicated the there had been at least one more eg in the original clutch.

The female Mallard flew off whe we approached the edge of the aspe grove. Three days later, June 11, sh refused to leave the nest until w shook the tree. In each instance sh disappeared through the dense foli age and flew at ground-level unt she was well out of sight. We did no see her return to the nest and won dered whether she landed directly o the nest from above, or whether sh landed at the base of the tree an then flew up to the nest edge. $\mathrm{Ha}$ anyone ever watched a tree-nestin Mallard return to her nest? It woul, be an interesting observation. 